12

\title{
Высокоэффективный источник электронов с полым катодом для технологий осаждения тонких пленок и обработки поверхностей при форвакуумных давлениях
}

\author{
(C) В.Г. Щукин, В.О. Константинов, В.С. Морозов
}

Институт теплофизики им. С.С. Кутателадзе СО РАН, 630090 Новосибирск, Россия

ฯ e-mail: konstantinov@itp.nsc.ru

\section{(Поступило в Редакцию 3 ноября 2017 г.)}

Показано, что в форвакуумном диапазоне давлений в источниках электронов с полым катодом возможно получать низкоэнергетические пучки с высоким КПД в широком диапазоне токов пучка. Путем вариации геометрических параметров электродной системы и электромагнитной оптики источника электронов удалось достичь КПД на уровне 0.9 при ускоряющем потенциале $1 \mathrm{kV}$ и токах пучка от 100 до $300 \mathrm{~mA}$. Определены параметры, наиболее сильно влияющие на КПД и стабильность работы источника электронов с полым катодом.

DOI: $10.21883 /$ JTF.2018.06.46025.2544

\section{Введение}

В настоящее время для осаждения тонких пленок кремния широко используются плазмохимические методы с активацией газообразного моносилана $\left(\mathrm{SiH}_{4}\right)$ в плазме электронного пучка [1]. Перспективность использования пучково-плазменного разряда представляет повышенный интерес в области плазмохимии, в частности для реализации технологий на основе плазменных методов получения покрытий [2]. Для генерации таких разрядов широко используются низкоэнергетические и высокоэнергетические источники электронов с энергиями до $40 \mathrm{keV}$ и свыше $100 \mathrm{keV}$ соответственно. Высокоэнергетические пучки могут быть как непрерывными, так и импульсными [3,4]. Такие пучки нашли широкое применение в процессах сварки $[5,6]$ и наплавки $[7,8]$, а также в процессах электронно-лучевого переплава для получения металлов и сплавов особой чистоты [9]. По сравнению с высокоэнергетическими низкоэнергетические источники имеют высокую плотность энергии пучка электронов, более низкие требования к радиационной защите, простоту выполнения высоковольтной изоляции, надежность и невысокую стоимость устройства.

Оба типа источников (как высокоэнергетические, так и низкоэнергетические) устойчиво работают преимущественно при глубоком вакууме, в то время как для плазмохимических технологий форвакуумный диапазон рабочих давлений является оптимальным с точки зрения достижения максимальной эффективности процесса. Использование этих источников в условиях глубокого вакуума возможно только при использовании нескольких ступеней дифференциальной откачки, что существенно усложняет вакуумное оборудование и увеличивает требования к конструкционным материалам установки.

Генерация низкоэнергетичных электронных пучков, обладающих высокими уровнем тока, вплоть до $1 \mathrm{~A}$, в форвакуумном диапазоне давлений является актуальной задачей. Одним из способов решения данной задачи является использование источников электронов на основе разряда с полым катодом. Электроны удерживаются в разрядном промежутке магнитным полем. Электростатическое удержание электронов в катодной полости приводит к резкому понижению напряжения горения разряда и увеличению его тока, а также к расширению рабочего диапазона давлений в область более низких значений [10].

К достоинствам плазменных источников электронов по сравнению с традиционно используемыми электронными пушками с твердотельным термоэмиссионным катодом следует отнести более высокую плотность эмиссионного тока, способность к импульсной эмиссии, более широкий диапазон давлений остаточного газа, не критичность к остаточной вакуумной среде и ряд других. Важная особенность плазменного катода состоит в возможности отбора из плазмы практически всех электронов, генерируемых в разрядном промежутке. Это обусловливает высокую эффективность эмиттера электронов такого типа. Такие источники конструктивно просты, долговечны и надежны. В отличие от электронных пушек с термокатодом они могут использоваться в агрессивных средах и при более высоких давлениях, при этом не происходит эрозии полого катода.

\section{Методика эксперимента}

Эксперименты проводили на газодинамической установке низкой плотности Института теплофизики CO РАН. В качестве генератора электронного пучка использовали источник электронов на основе разряда с полым катодом, разработанный в Институте под руководством Р.Г. Шарафутдинова [1,11]. 


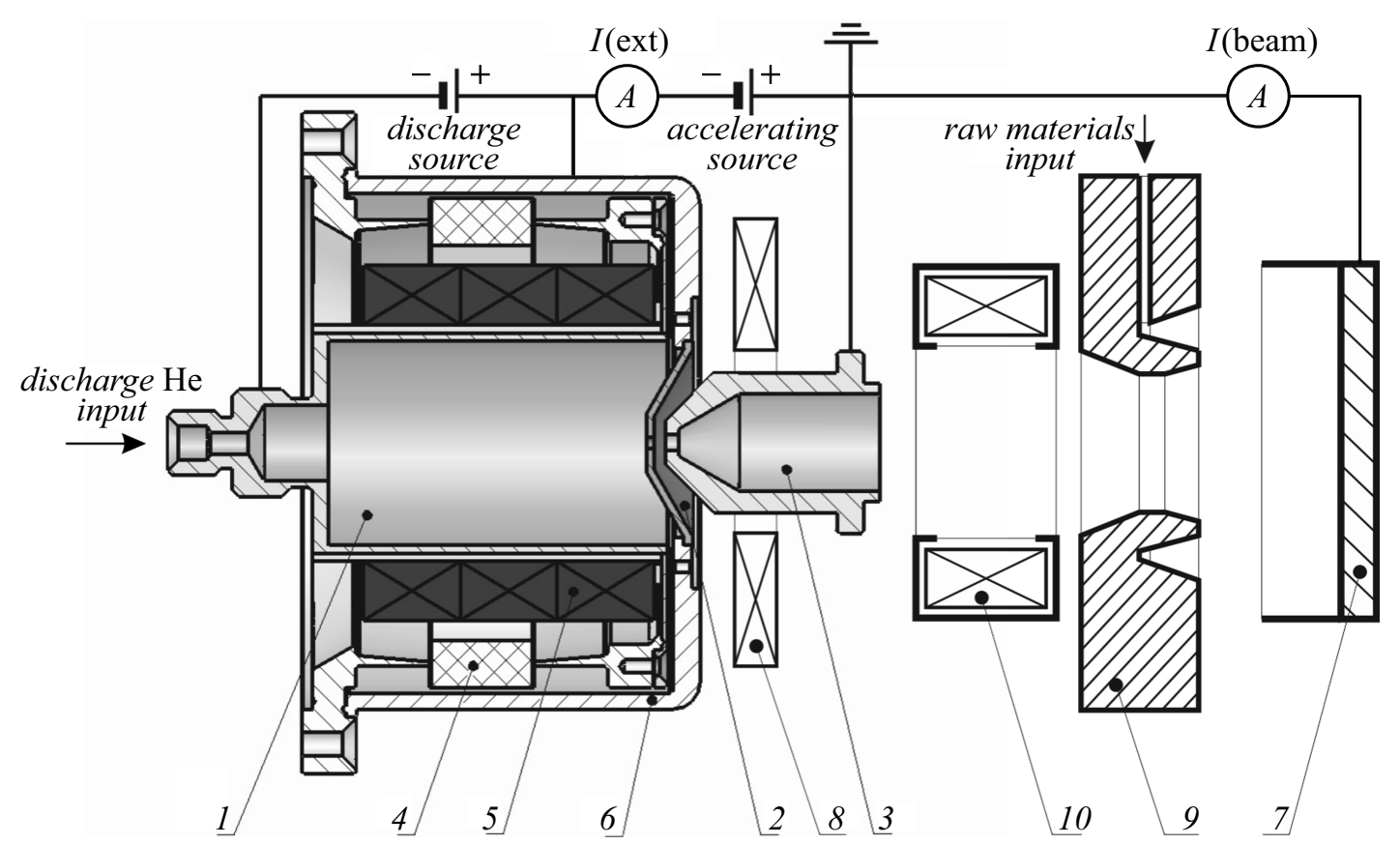

Рис. 1. Электродная конфигурация разрядной системы: 1 - полый катод, $2-$ анод, 3 - ускоряющий электрод, $4-$ керамический изолятор, 5 - постоянные магниты, 6 - магнитопровод, 7 - коллектор электронов, 8 - корректирующая линза, $9-$ сопловой блок, $10-$ панцирная магнитная линза.

Электродная конфигурация разрядной системы приведена на рис. 1 и включает в себя полый катод 1 , анод 2 из нержавеющей стали с диаметром отверстия $d(a)$ и ускоряющий электрод 3 , выполненный из меди, с диаметром отверстия $d(\mathrm{ext})$. Анод располагали относительно ускоряющего электрода на расстоянии $L(a-\mathrm{ext})$.

Для электрической развязки полого катода и анода в конструкции источника использован керамический изолятор 4. Для создания повышенной электронной плотности на оси полый катод „погружен“ в магнитное поле, создаваемое постоянными магнитами 5 . Поверхность разрядной камеры и постоянные магниты охлаждали проточным вакуумным маслом. Магнитопровод 6 служил для замыкания магнитного поля внутри полого катода, а также для поддержания устойчивого разряда. Разрядный газ (гелий) подавали непосредственно в полый катод. Электронный пучок формировали путем приложения потенциала $U$ величиной минус $1 \mathrm{kV}$ к аноду относительно заземленного ускоряющего электрода. Количество электронов, выходящих из электронной пушки, определялось значением тока $I(\mathrm{ext})$, задаваемого высоковольтным источником питания. Для измерения количества электронов, попадающих из электронной пушки в реакционную камеру, в ней установлен коллектор электронов 7 (цилиндр Фарадея). Ток пучка электронов изменялся в диапазоне от 100 до $300 \mathrm{~mA}$, при этом диаметр первичного пучка электронов в области вхождения в цилиндр Фарадея составлял 5-10 mm.
Таким образом, измеряя ток $I(\mathrm{ext})$ и ток пучка электронов $I($ beam), определяли КПД электронной пушки по формуле: КПП $=\frac{I(\text { beam })}{I(\text { ext })}$. Регулировку тока пучка производили путем изменения расхода разрядного гелия.

Для фокусировки пучка электронов в области входа в ускоряющий электрод использовали корректирующую линзу 8 - короткую магнитную линзу-катушку. Оптимальную для провода сквозь кольцевой сопловой блок подачи сырья 9 форму пучка электронов достигали за счет изменения фокусного расстояния при помощи панцирной длинной магнитной линзы с медным окном 10.

Кольцевой сопловой блок подачи сырья представлял собой сверхзвуковое кольцевое сопло Лаваля. Его использовали для подачи в реакционную камеру рабочих газов, из которых в результате плазмохимических реакций формируются слои на поверхности или происходит их обработка.

На рис. 2 приведена фотография электронной пушки с сопловым блоком, а на рис. 3 - фотография электронного пучка с энергией $1 \mathrm{keV}$ и током $150 \mathrm{~mA}$ при различных значениях тока панцирной длинной магнитной линзы с медным окном. При увеличении тока линзы форма пучка электронов меняется со спицевидной (рис. $3, a$, ток на линзу составлял $20 \mathrm{~mA}$ ) на конусообразную (рис. 3, $c$, ток $-60 \mathrm{~mA}$ ). В результате увеличения тока на линзу фокус пучка электронов смещается в сторону его выхода из источника. Для применения в технологиях осаждения слоев расфокусированный конусообразный пучок является предпочтительным, в то время как для 


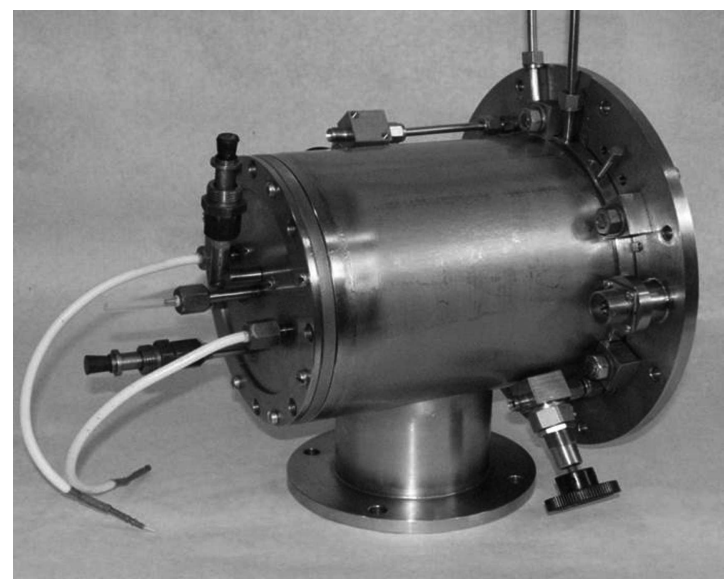

Рис. 2. Фотография электронной пушки с сопловым блоком.
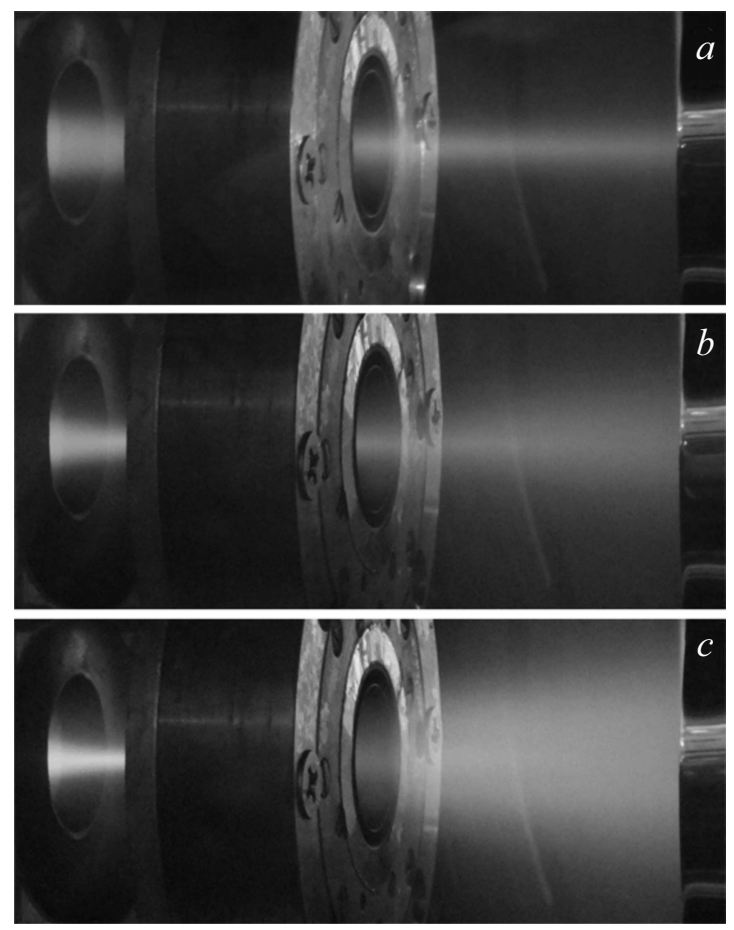

Рис. 3. Фотография электронного пучка с энергией $1 \mathrm{keV}$ и током $150 \mathrm{~mA}$.

обработки поверхностей больше подходит сфокусированный пучок.

Для нахождения оптимальных параметров электронной оптики изменяли следующие параметры: диаметр центрального отверстия в аноде, диаметр центрального отверстия в ускоряющем электроде, расстояние между анодом и ускоряющим электродом, а также положение анода относительно постоянных магнитов разрядной системы.

Ранее нами были достигнуты КПД на уровне 0.99 при токах пучка в диапазоне от 100 до $600 \mathrm{~mA}$ при ускоряющем потенциале $4 \mathrm{kV}$ [11]. Настоящая работа была направлена на достижение максимальных значений КПД при токах пучка в диапазоне от 100 до $300 \mathrm{~mA}$ при ускоряющем потенциале $1 \mathrm{kV}$ в форвакуумном диапазоне давлений.

\section{Результаты и дискуссия}

КПД электронной пушки зависит от энергии пучка электронов, особенно сильно это проявляется в форвакуумном диапазоне давлений. Это связано с тем, что при повышении давления происходит рассеяние низкоэнергетичных пучков электронов на молекулах фонового газа, приводящего к изменению траектории электронов пучка. Воздействовать на форму пучка электронов, и как следствие на КПД электронной пушки, можно при помощи геометрии электродов и их взаимного расположения.

На рис. 4, $a$ и 4, $b$ приведена схема электродной системы электронной пушки, где $X-$ расстояние до „носика“ анода относительно среза магнитов.

При значениях $X>0$ носик анода находится внутри постоянного однородного осесимметричного магнитного поля, сформированного постоянными магнитами, окружающими разрядную камеру. При этом рожденные в разрядной камере электроны концентрируются вдоль осевой линии этой камеры на расстоянии, не превышающем дебаевский радиус (рис. 4,a). Траектории движения электронов показаны на рисунке линиями. Эти условия являются наиболее благоприятными для получения максимального тока эмиссии, при котором большая часть электронов разряда попадает в область ускорения. При уменьшении значения $X$ (выход „носика“ анода на срез магнитов и за их пределы) происходит уменьшение напряженности магнитного поля на оси разрядной камеры, что приводит к увеличению радиуса концентрации электронов вдоль этой оси (рис. 4, $b$ ). Это, в свою очередь, влечет за собой потерю части электронов разряда на аноде [12].

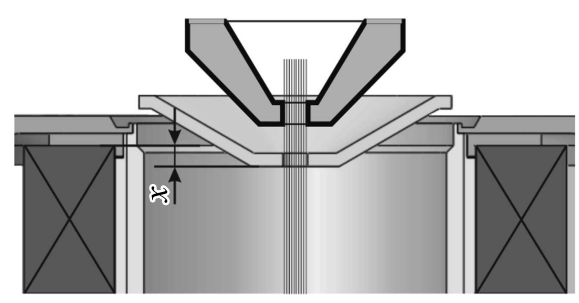

$a$

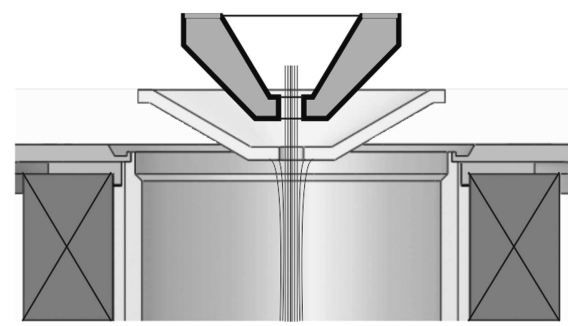

$b$

Pис. 4. Схема электродной системы электронной пушки. 


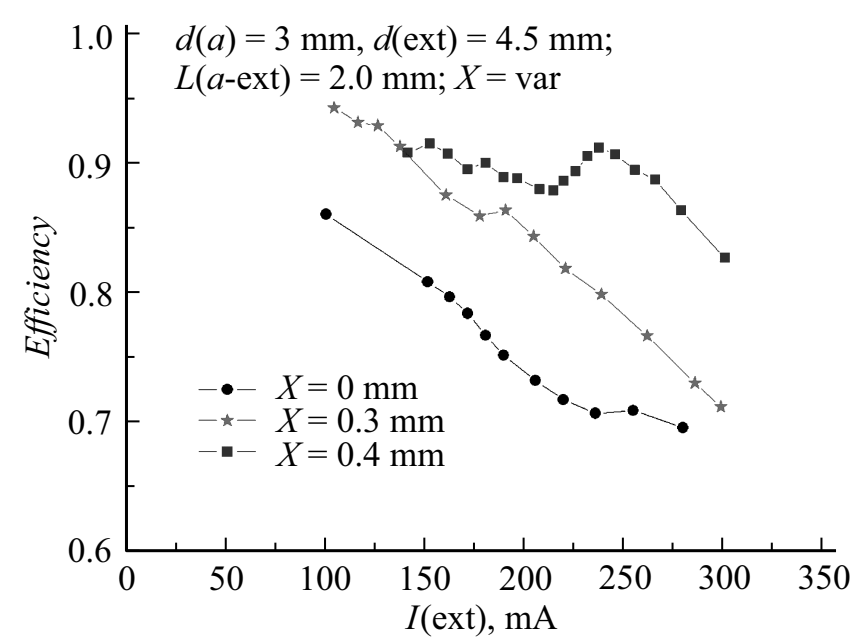

Рис. 5. Зависимости КПД электронной пушки от положения „носика“ анода относительно среза магнитов.

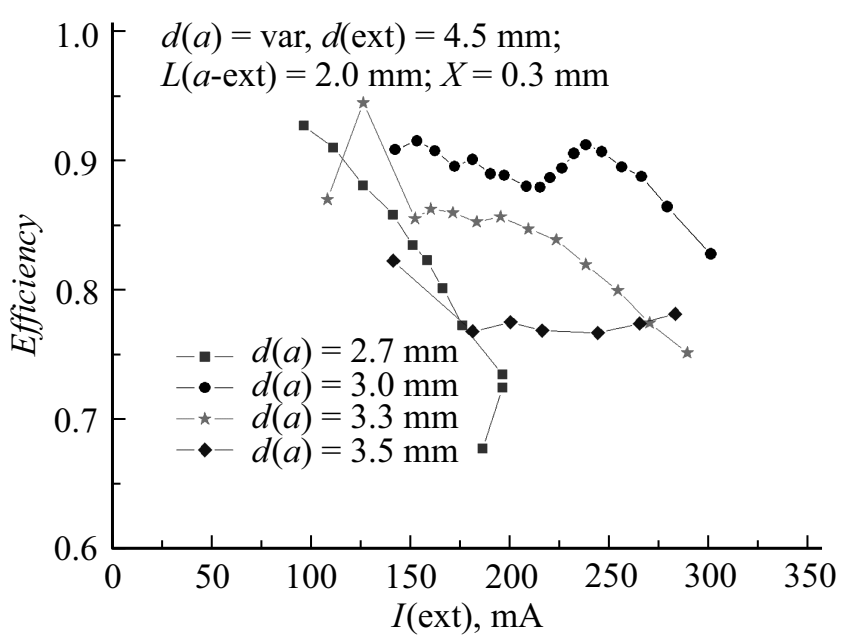

Рис. 6. Зависимости КПД электронной пушки от диаметра отверстия в аноде.

На рис. 5 представлены зависимости КПД электронной пушки от положения „носика“ анода относительно среза магнитов разрядной камеры при различных значениях тока $I(\mathrm{ext})$, задаваемого высоковольтным источником питания.

Из рисунка видно, что при погружении „носика“ анода внутрь магнитного поля КПД электронной пушки увеличивается, приближаясь к значению 0.9, при этом характеристика становится более пологой в исследуемом диапазоне токов. Наблюдаемое поведение характеристик соответствует высказанному выше предположению. Необходимо отметить, что дальнейшее увеличение параметра $X$ является затруднительным, это связано с тем, что при уменьшении расстояния между катодом и анодом возрастает вероятность электрического пробоя этого промежутка.
Влияние диаметра отверстия в аноде $d(a)$ на величину КПД электронной пушки при различных токах $I($ ext) приведено на рис. 6.

Из взаимного расположения характеристик видно, что величина КПД имеет экстремум при диаметре отверстия в аноде, равном $3 \mathrm{~mm}$. При уменьшении или увеличени этого диаметра происходит снижение значения КПД в диапазоне исследуемых токов $I(\mathrm{ext})$. Такое поведение характеристик можно объяснить механизмом эмиссии электронов из плазмы [10]. Если эмиссионное отверстие, в нашем случае $d(a)$, меньше протяженности слоя пространственного заряда, слои перекрывают эмиссионное отверстие, при этом эмиссия электронов осуществляется через потенциальный барьер. В этом случае эффективность извлечения электронов мала, что и наблюдается при малом диаметре отверстия в аноде. Как следствие, значения КПД электронной пушки малы. В случае, когда слой пространственного заряда мал по сравнению с эмиссионным отверстием, открытая плазменная поверхность занимает практически всю площадь эмиссионного отверстия. Эффективность извлечения тока близка к единице, однако степень возмущения параметров плазмы оказывается высокой, что затрудняет получение электронного пучка со стабильными параметрами. В нашем случае это наблюдается при большом диаметре отверстия в аноде. При достаточно высоких значениях КПД электронная пушка ведет себя нестабильно, характеристики становятся резкими. Из изложенного выше следует, что в промежуточном варианте при достаточно большой эффективности извлечения электронов изменение параметров плазмы, сопровождающее процесс эмиссии электронов, будет не столь велико. Это позволит получить стабильный пучок электронов при максимальном значении КПД электронной пушки, что продемонстрировано на рис. 6.

Зависимость значений КПД электронной пушки от диаметра отверстия в ускоряющем электроде $d(\mathrm{ext})$ приведена на рис. 7.

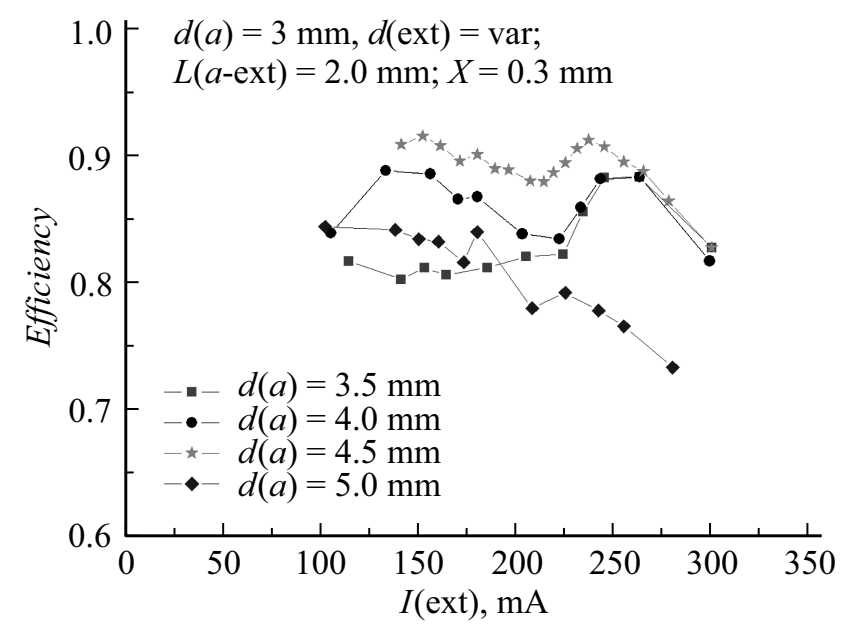

Рис. 7. Зависимости КПД электронной пушки от диаметра отверстия в ускоряющем электроде. 


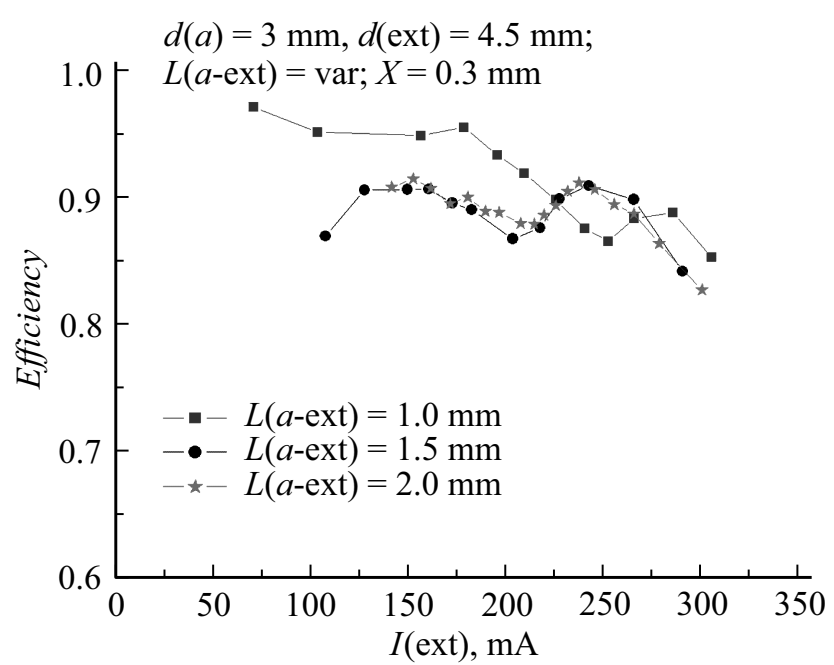

Рис. 8. Зависимости КПД электронной пушки от расстояния между анодом и ускоряющим электродом.

При увеличении $d(\mathrm{ext})$ до определенного значения наблюдается увеличение значения КПД электронной пушки во всем диапазоне исследуемых токов $I($ ext), что можно связать с изменением геометрии ускоряющего промежутка, которое выражается в уменьшении количества электронов, гибнущих на „носике“ ускоряющего электрода. При значении $d(\mathrm{ext})$, равном $4.5 \mathrm{~mm}$, большее количество электронов проходит область ускоряющего электрода, не касаясь внутренней его поверхности, и формирует электронный пучок. Угол разлета электронов, выходящих из анода, определяется диаметром отверстия в ускоряющем электроде и ускоряющим потенциалом. При фиксированном ускоряющем потенциале с увеличением диаметра отверстия ускоряющего электрода происходит увеличение угла разлета электронов за счет электростатических сил. В нашем случае при значении $U$, равном $1 \mathrm{kV}$, гибель электронов на внутренней поверхности ускоряющего электрода начинается при $d($ ext), превышающем $4.5 \mathrm{~mm}$.

Помимо геометрических характеристик ускоряющего промежутка на КПД электронной пушки влияет корректирующая электромагнитная линза, расположенная на ускоряющем электроде. За счет управляемого изменения величины магнитного поля, приводящего к сдвигу фокусного расстояния электронного пучка в область внутри ускоряющего промежутка, удалось достичь оптимального угла разлета электронов в широком диапазоне токов $I($ ext $)$, что невозможно без использования корректирующей линзы из-за саморасфокусировки электронного пучка при больших значениях тока.

Поведение характеристик, приведенных на рис. 8, полностью объясняется взглядами, изложенными при описании рис. 7. Только в этом случае угол разлета электронов определяет расстояние между анодом и ускоряющим электродом. Несмотря на то, что при $L(a-\mathrm{ext})$, равном $1 \mathrm{~mm}$, значения КПД выше, для практического применения характеристики с $L(a$-ext), равном 1.5 и $2 \mathrm{~mm}$, предпочтительнее ввиду постоянства значений в широком диапазоне исследуемых токов.

\section{Заключение}

Проведенное исследование показало, что для достижения высоких значений КПД электронной пушки при невысоких энергиях требуется оптимизация геометрических параметров элементов электродной системы для каждого ускоряющего потенциала, а также использование корректирующих систем на основе электромагнитных линз.

При выборе геометрических параметров электродной системы необходимо „погружать“ плоскость эмиссионного отверстия в постоянное магнитное поле в объеме полого катода разрядной системы электронной пушки. Также необходимо подбирать оптимальное соотношение между диаметром эмиссионного отверстия и протяженностью слоя пространственного заряда, сформированного на поверхности анода. Диаметр отверстия в ускоряющем электроде и его расположение относительно анода сильно влияют на КПД электронной пушки и должны выбираться с учетом геометрии анода.

В ходе выполнения работы получен стабильный непрерывный электронный пучок с энергией $1 \mathrm{keV}$ и током от 100 до $300 \mathrm{~mA}$ в форвакуумном диапазоне давлений, при этом достигнутое значение КПД электронной пушки составило 0.9. Такие пучки активно применяются в процессах осаждения различных пленок и обработки поверхностей для изменения их свойств.

Работа выполнена при поддержке РФФИ и Министерства образования, науки и инновационной политики Новосибирской области (проект № 17-48-540665 p_a).

\section{Список литературы}

[1] Sharafutdinov R.G., Khmel S.Ya., Shchukin V.G. et al. // Solar Energy Materials \& Solar Cells. 2005. Vol. 89. N 20-3. P. 99 111.

[2] Anders A. // Surface \& Coatings Technology. 2005. Vol. 200. P. 1893-1906.

[3] Астрелин В.Т., Бурдаков А.В., Деревянкин Г.Е. и др. // Плазменная эмиссионная электроника: Труды III Международного крейнделевского семинара. Улан-Удэ, 2009. C. $74-80$.

[4] Кандауров И.В., Куркучеков В.В., Трунев Ю.А. // Плазменная эмиссионная электроника: Труды IV Международного крейнделевского семинара. Улан-Удэ, 2012. С. 67-73.

[5] Волков А.А., Пчёлкин Р.Д., Ремпе Н.Г. // Сварочное производство. 2001. № 1. С. 23-28.

[6] Васильков В.И., Кислицкий А.А., Онучин Н.В. и др. // Автоматическая сварка. 2002. № 6. С. 38-40.

[7] Bugaev A.S., Vizir A.V., Gushenets V. et.al. // Laser and Particle Beams. 2003. Vol. 21. N 2. P. 139-156.

[8] Панин В.Е., Белюк С.И., Дураков В.Г. и др. // Сварочное производство. 2000. № 2. С. 34-38. 
[9] Тихоновский А.Л., Тур А.А. Рафинирование металлов и сплавов методом электронно-лучевой плавки. Киев: Наукова думка, 1984. 272 с.

[10] Окс E.M. Источники электронов с плазменным катодом: физика, техника, применение. Томск: Изд-во НТЛ, 2005. $216 \mathrm{c}$.

[11] Konstantinov V.O., Sharafutdinov R.G., Karsten V.M. // Contributed papers of $\mathrm{V}$ International Conference on Plasma Physics and Plasma Technology. 2006. Minsk, Belarus. Vol. 1. P. $276-279$.

[12] Груздев В.А., Залесский В.Г. // Прикладная физика. 2009. № 5. P. 82-90. 